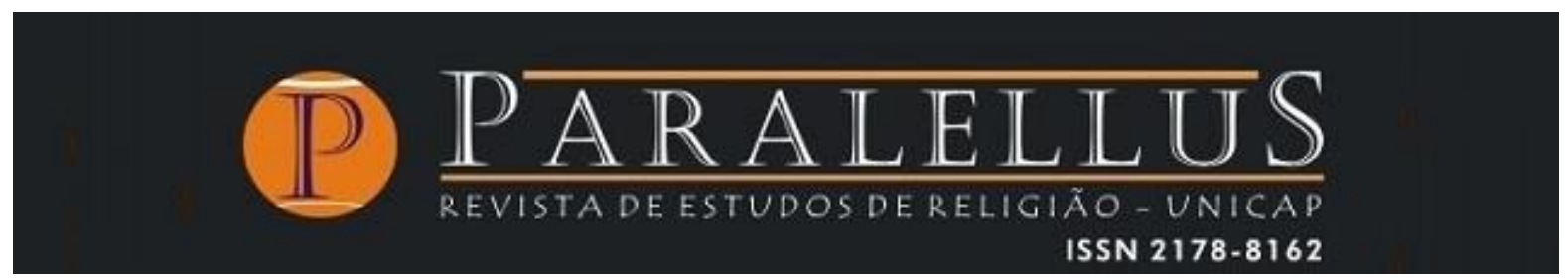

Volume 12 - Número 30

DOSSIÊ: INTERPRETAÇÃO PLURALISTA DAS RELIGIÕES

doi: 10.25247/paralellus.2021.v12n30.p415-432

\title{
ONDE ESTÁ A SABEDORIA? (JÓ 28,12): OS LIMITES DO CONHECIMENTO HUMANO
}

\author{
WHERE IS THE WISDOM? (JOB 28:12): THE LIMITS OF HUMAN \\ KNOWLEDGE
}

Prof ${ }^{a}$ Dr ${ }^{a}$ Aíla Luzia Pinheiro de Andrade*

Prof. MSc. Augusto Lívio Nogueira de Morais**

\section{RESUMO}

É de suma importância conhecer o desenvolvimento histórico do sistema sapiencial no antigo Israel para compreender o contexto do surgimento do cristianismo dentro do judaísmo plural no período do segundo Templo. Sendo assim, o artigo tem como objetivo pesquisar a crise sapiencial e suas repercussões teológicas e sociológicas não somente para os séculos VI aC - I dC, mas também para as gerações futuras. $O$ estudo foi realizado através da pesquisa bibliográfica de natureza qualitativa e com enfoque hermenêutico. A pesquisa tem por base teórica os textos bíblicos BÍBLIA (2002), com o estudo do vocabulário hebraico em STRONG (1995), uma visão geral sobre o desenvolvimento do movimento sapiencial a partir de ASENSIO (2008) e a inacessibilidade da sabedoria no livro de Jó tomando por base a tese de DELL (1991). O artigo está estruturado em dois momentos principais: o desenvolvimento da sabedoria até sua identificação com a Torá; as questões sobre acessibilidade e inacessibilidade da sabedoria. Os resultados obtidos com a pesquisa destacam que após perceberem a acessibilidade da sabedoria que se manifesta tanto na criação (sua universalidade) quanto na sua identificação com a Torá (sua particularidade), os sábios do

\footnotetext{
* Doutora em teologia bíblica pela Faculdade Jesuíta de Filosofia e Teologia (FAJE), membro do Programa de Pós-graduação em Teologia da Universidade Católica de Pernambuco (UNICAP).

** Mestre em Teologia com concentração em Literatura Bíblica e Teológica - interpretações, pela Universidade Católica de Pernambuco (UNICAP). Professor no curso de Teologia da Faculdade Católica do Rio Grande do Norte (FCRN), na área de Sagradas Escrituras.
} 
antigo Israel chegaram à conclusão que é na experiência existencial com o Senhor que o ser humano encontra a sabedoria.

Palavras-chave: Ética; Temor do Senhor; Torá; Livro dos Provérbios; Sabedoria.

\section{ABSTRACT}

It is very important to know the historical development of the sapiential system in ancient Israel to understand the context of the emergence of Christianity within plural Judaism in the period of the second Temple. Thus, this article aims to investigate the sapiential crisis and its theological and sociological repercussions not only for the 6th century BC - 1st AD, but also for future generations. The study was carried out through bibliographic research of a qualitative nature and with a hermeneutic focus. The research is based on biblical texts BÍBLIA (2002), with the study of the Hebrew vocabulary in STRONG (1995), an overview on the development of the sapiential movement in ASENSIO (2008) and the inaccessibility of wisdom in the book of Job based on DELL's thesis (1991). The article is structured in two main moments: the development of wisdom until its identification with the Torah; the questions about accessibility and inaccessibility of wisdom. The results obtained with the research highlight that after realizing the accessibility of the wisdom that manifests itself both in creation (its universality) and in its identification with the Torah (its particularity), the sages of ancient Israel, came to the conclusion that it is in the existential experience with the Lord that the human being finds wisdom.

Keywords: Ethic; The fear of the Lord; Torah; Book of Proverbs; Wisdom.

\section{INTRODUÇÃO}

Quando se pensa em sabedoria, é comum associar essa palavra à ideia de inteligência, de erudição, de um conhecimento profundo das coisas, que vai além das ideias básicas e superficiais que a maioria das pessoas geralmente têm sobre algum assunto.

Entretanto, dentro da tradição sapiencial presente na Bíblia, a sabedoria pode ser identificada com a busca do ser humano por autocompreensão em suas relações com as coisas, com as pessoas e com o Criador. Isso significa que a sabedoria tem uma conotação prática, e seu objetivo é orientar o ser humano nas questões de sobrevivência e bem-estar. É um conhecimento proveniente da experiência existencial com os princípios que governam a vida pessoal, a comunidade humana e o universo. Sábio é quem adquiriu a habilidade para viver o "temor do Senhor" no enfrentamento dos desafios provenientes da natureza, da vida social e da história pessoal. 
Uma ampla variedade de situações levou os sábios do período veterotestamentário a um processo que foi identificando a sabedoria com a Lei mosaica, a Torá. A sabedoria estava à mão, era acessível a todas as pessoas. Porém, em certo período do contexto do pós-exílio a situação ficou nebulosa e a acessibilidade da sabedoria ao ser humano foi posta em questão.

Para conhecer esse processo histórico é necessário debruçar-se sobre as etapas que permitiram chegar a essas questões e tentar compreender as implicações que estão presentes na concepção de sabedoria na tradição bíblica.

\section{A SABEDORIA COMO UMA HABILIDADE PRÁTICA}

Geralmente se pensa na sabedoria como um conhecimento erudito ou ainda como uma ética, uma conduta para vida baseada no discernimento sobre o que é bom ou mau, certo ou errado.

Entretanto, na literatura do Antigo Testamento há uma compreensão a respeito da sabedoria que vai além da erudição e da ética, a saber, a preocupação com questões práticas da vida. A sabedoria é apresentada como um conhecimento relacionado ao domínio de técnicas ou a ações para o desenvolvimento da vida das pessoas.

É possível identificar uma variedade de textos nos quais os termos sábio (hakam) e sabedoria (hokmah) aparecem relacionados a diversas situações práticas da vida (STRONG, 1995, p. 43). Os artesãos, por exemplo, com sua técnica de trabalho, são chamados de sábios e seu conhecimento técnico é entendido como uma forma de sabedoria (Is 3,3; 40,20; Ex 36,4; Jr 10,9; 1Cr 22,15). Juntamente com os artesãos, outras atividades e o domínio da técnica necessária para realizá-las podem ser consideradas como uma forma de sabedoria: timoneiros (Ez 27,8), carpideiras (Jr 9,16), legisperitos (Jr 8,8; Dt 1,13; 16,19), o exercício do governo (1Rs 3,8-12).

Esse tipo de conhecimento prático ou técnico exigia habilidades específicas de seus executores. Como nem todas as pessoas dominavam tais técnicas, as que as dominavam assumiam a posição de peritos ou de sábios em sua área. Note-se que nesse contexto não entra em questão valores éticos, mas o domínio de uma técnica específica (SÆEBØ, 1985, col. 778). 
Pode-se incluir aqui também a astúcia e a engenhosidade para a autoconservação, independente de valores éticos. O objetivo, nessa situação, é obter o resultado que seja favorável para a pessoa diante de uma situação difícil, perigosa ou mortal. Dois casos interessantes podem ilustrar isso. São casos em que mulheres agem de forma sábia para conseguir alterar uma situação grave, com risco de morte.

O primeiro caso é a obtenção do perdão para Absalão (2Sm 14). Aqui encontra-se a figura de uma mulher de Técua, que é chamada por Joab por ser ela sábia (hakam) $(2 S m ~ 14,2)$. Ela se apresenta diante do rei Davi e utilizando um artifício no seu discurso convence o rei a receber de volta o filho que tentou usurpar o trono. No outro caso, estamos diante do cerco de Joab a cidade de Abel-Bet-Maaca com o objetivo de capturar Seba, filho de Bocri, que se revoltou contra o rei Davi (2Sm 20,14-22). Uma mulher dirige-se a Joab e intercede pela cidade. Joab afirma que se eles entregarem Seba a cidade não sofrerá nada. Então, a mulher com sua sabedoria (hokmah) convence os habitantes da cidade e eles entregam a cabeça de Seba a Joab (2Sm 20,22).

Nesses dois exemplos o uso dos termos sábio e sabedoria está associado à astúcia e a engenhosidade para a sobrevivência. Não é feita nenhuma alusão ética, mas o que se tem como objetivo é o resultado desejado em benefício de alguém ou de alguma situação.

Outro exemplo está no livro dos Provérbios quando se trata a respeito do suborno. Para o campo ético moderno, o suborno é um tema negativo, algo ruim em si mesmo, por se apresentar como uma prática desonesta de corrupção. Entretanto, o texto bíblico não trata desse tema sob essa perspectiva. Em um contexto em que o rei era o poder central e tudo dependia de sua vontade, o livro dos Provérbios apresenta o suborno como um caminho positivo para se alcançar um objetivo desejado $(\operatorname{Pr} 14,35$; $17,8 ; 18,16 ; 21,14)$. Por meio do suborno, a pessoa poderia abrir caminho para ter acesso ao rei, alcançar algum favor ou benefício da parte do rei ou obter sucesso em algum empreendimento. Essa posição parece contraditória, mas é preciso perceber que naquele contexto a sabedoria tem uma função pragmática, não ética. Aqui, é o objetivo a ser alcançado que está em questão e o sábio é aquele que tem a habilidade para alcançá-lo e essa habilidade é identificada como uma forma de sabedoria. 
Por outro lado, no mesmo livro dos Provérbios encontra-se uma crítica à prática do suborno (Pr 15,27), associando o ódio ao suborno com a garantia de permanecer vivo. Isso significa uma evolução na compreensão desse tema, visto que o livro dos Provérbios teve sua composição em um longo período de tempo, em que tradições orais foram sendo registradas. É natural que tradições mais antigas tenham posturas mais preocupadas com a sobrevivência em ambiente hostil que com questões éticas (SILVA, 2019, p. 15).

\section{A SABEDORIA E O CAMPO ÉTICO}

A sabedoria assume, gradativamente, uma perspectiva mais ampla que vai mudando em relação à abordagem mais prática associada ao domínio de uma técnica específica ou a astúcia para alcançar objetivos movendo-se pela vida entre o bem e o mal.

Surge uma compreensão de sabedoria como sendo o conhecimento da ordem estabelecida por Deus na criação e que o verdadeiro sábio é aquele que conhece essa ordem e vive segundo o que ela determina ${ }^{1}$. Desse modo, a pessoa pode ter uma vida abençoada por Deus, próspera e feliz.

Dentro dessa perspectiva, encontramos duas abordagens: uma acredita que o ser humano é capaz de alcançar essa sabedoria por seu próprio esforço, e outra que vê a sabedoria como um dom de Deus e, assim sendo, a pessoa precisa abrir-se a esse dom por meio de uma atitude religiosa de submissão a Deus e a sua vontade ${ }^{2}$.

Essas duas abordagens não se excluem mutuamente, mas em vários momentos elas se cruzam dentro da tradição sapiencial bíblica presente no Antigo Testamento. Neste ponto, é necessário analisar de modo mais acurado cada uma delas para entender a dinâmica das relacionações entre elas.

\subsection{A sabedoria é um bem ao alcance do ser humano}

1 "Debe aclararse aquí que no hablamos de "cosmos", en el sentido griego, como si el universo se tratara de un reloj autómata y Dios de su relojero. No. El israelita comprende ese "orden" en el sentido de "gracia"' (VALERIO, 2018, p. 14).

2 Sabio es quien, comprendiéndose criatura, trata de entender su mundo, sacarle al caos una parcela de orden y vivir según la voluntad del Dios de Israel (VALERIO, 2018, p. 13).

Paralellus, Recife, v. 12, n. 30, mai./ago. 2021, p. 415-432 
Ao colocar uma ordem na criação, Deus deixou ao ser humano a responsabilidade de identificar essa ordem e, consequentemente, viver de acordo com ela. Uma vez que ele faça isso será feliz, caso contrário irá perecer.

Deus, no seu ato criador, estabeleceu uma ordem; e confiou ao homem seu descobrimento e manutenção. O caminho da sabedoria conduz ao descobrimento e à aceitação da citada ordem. Quem se ajusta a ela será feliz; quem resiste está fadado à autodestruição (ASENSIO, 2008, p. 38)

Essa perspectiva coloca sobre o ser humano a responsabilidade em buscar a sabedoria e em relação às consequências para sua própria vida.

Assim sendo, o ser humano deve adquirir a sabedoria como quem busca um bem mercantil, utilizando tudo o que estiver ao seu alcance para alcançá-la $(\operatorname{Pr} 4,5-7 ; 2,4$; 16,16). Ou como alguém que busca encontrar o objeto de seu amor a sabedoria deve ser amada, buscada, abraçada ( $\operatorname{Pr} 4,6-8$; Eclo 14,20-27; Ct 2,9). Essa busca é incentivada porque se acredita que a sabedoria está ao alcance do esforço humano: "Se quiseres, filho, tu te instruirás; e tua docilidade te proporcionará a habilidade" (Eclo $6,32)$.

Uma vez que a pessoa tenha alcançado a sabedoria ela será capaz de viver sua vida em plenitude: "Feliz o homem que encontrou a sabedoria, o homem que alcançou o entendimento! Ganhá-la vale mais do que a prata, e o seu lucro mais do que o ouro" (Pr 3,13-14).

Pode-se perceber que há um otimismo em relação ao acesso humano à sabedoria. $\mathrm{O}$ sábio, nesse contexto, é alguém que conseguiu, por seu esforço, sondar a ordem estabelecida por Deus na criação. Uma vez em posse desse conhecimento ele não só terá uma vida feliz, pois pode proceder de acordo com a vontade do criador manifesta na ordem da criação (VALERIO, 2018, p. 14), mas também se torna capaz de ensinar aos outros, especialmente às novas gerações, o que aprendeu para que estes também alcancem essa sabedoria e sejam felizes.

Entretanto, essa postura não é absoluta. É possível encontrar sentenças em que o trabalho humano e a ação divina como assistência na busca da sabedoria aparecem relacionados $(\operatorname{Pr} 16,1-3 ; \operatorname{Pr} 3,5)$. 


\subsection{0 dom da sabedoria e o temor do Senhor}

O tema do temor do Senhor relacionado com sabedoria surge como uma forma de enfrentar dois problemas que o otimismo na capacidade humana para alcançar a sabedoria não foi capaz de responder.

O primeiro trata da ordem presente na criação. No livro de Jó encontramos a crítica de que essa ordem seria uma ilusão, na verdade o que existe é o caos, o sofrimento e, desse modo, se põe em dúvida a justiça de Deus e sua capacidade de retribuir com felicidade e prosperidade aqueles que buscam viver conforme essa suposta ordem (DELL, 1991, p. 189).

O segundo problema vem da afirmação, presente em Jó e Eclesiastes, de que é ilusória a esperança humana de alcançar a sabedoria por suas próprias forças. Desse modo, toda busca empreendida pelo conhecimento é ilusória, fadada ao fracasso (DELL, 1991, p. 75).

O tema do temor do Senhor se apresenta como tentativa de superar esses dois problemas e garantir a justiça divina e o acesso do ser humano à sabedoria.

Em $\operatorname{Pr} 1,7$ se destaca que "O temor do Senhor é princípio de conhecimento" ${ }^{3}$. Sendo assim, para o ser humano se tornar sábio ele precisa entrar em um caminho de submissão a Deus, a sua vontade. Em Eclesiástico (Eclo 1,1.10cd), novamente encontramos a mesma perspectiva, porém reforçando que a verdadeira sabedoria vem de Deus. A sabedoria tem em Deus sua origem e Ele a concede aos que o temem, em outras palavras, a sabedoria é um dom.

Outra coisa importante, presente no tema do temor do Senhor, é a consciência da condição humana de criatura, de ser limitado. Para alcançar a sabedoria, o ser humano precisa abrir-se para Deus e esperar dele o dom da sabedoria. É ela quem deve apresentar-se ao ser humano como dom. Para Eclesiástico, tanto a sabedoria como o temor do Senhor são dons concedidos por Deus para que o ser humano seja feliz, tenha segurança, bem-estar e saúde por toda sua vida (Eclo 1,12.18.20; FOX, 2000, p. 114).

${ }^{3}$ Esse princípio vai se repetir várias vezes em quase todos os livros sapienciais. 
Assim, essa relação entre sabedoria e temor do Senhor coloca a sabedoria no campo religioso, relacionado à fé de Israel em seu Deus e na forma como é vivida essa relação com Ele. Há, de certo modo, uma teologização da sabedoria, retirando-a do campo prático da vida cotidiana e, apesar de manter a relação com o campo ético, agora a sabedoria se vê inserida no campo religioso e é o ser humano religioso que tem condições de ter acesso a ela por meio de temor do Senhor.

\section{A SABEDORIA E A TORÁ}

Em Eclo 24 há uma mudança significativa sobre o tema da sabedoria. Aqui, a sabedoria faz um discurso que é um autoelogio no qual mostra onde pode ser encontrada e o que as pessoas precisam fazer para adquiri-la. A sabedoria "fala de sua própria natureza excelsa, na qualidade de quem nasceu de Deus" (CERESKO, 2004, p. 145) da boca do Altíssimo (v. 3), de quem recebeu ordens para se fixar no Templo de Jerusalém (v. 8-12).

A sabedoria foi criada por Deus, mas não permaneceu na esfera divina. Deus a enviou para a terra, porém, não para qualquer lugar, mas para que ela habitasse no meio do povo de Israel. Podemos perceber um processo de nacionalização da sabedoria, ela habita no povo de Israel, entre eles Deus armou a tenda para ela.

Entretanto, o texto ainda vai além, pois a sabedoria não somente habita no povo de Israel, mas ela assume um lugar específico, que permite a todos que a desejarem poder encontrá-la. A sabedoria, com toda sua beleza e fartura (Eclo 24,14-22) encontra-se no livro da Lei, ou melhor, "Tudo isto é o livro da aliança do Deus Altíssimo, a Lei que Moisés promulgou, a herança para as assembleias de Jacó" (Eclo 24,23; DELL, 1991, p. 198).

Ao identificar a sabedoria com a Lei, o modo para adquiri-la passa a ser o conhecimento e a prática da Lei. Meditá-la dia e noite $(S I 1,2)$ tornará a pessoa sábia, pois com ela se aprende o temor do Senhor e a forma como se deve proceder para se viver bem: "A boca do justo medita a sabedoria e sua língua fala o direito; no seu coração está a lei do seu Deus, seus passos nunca vacilam" (SI 37,30-31). 
Por meio da Lei, Deus entregou ao povo de Israel a sabedoria, criada por ele desde o princípio e por meio de quem Ele realizou a obra da criação. Agora ela encontra-se presente, habitando a casa de Jacó e acessível ao povo da aliança.

\section{A SABEDORIA É ACESSÍVEL OU INACESSÍVEL?}

Apesar de o Eclesiástico identificar a sabedoria com a Torá mosaica, há evidências de uma tradição sapiencial de conotação ética que não identifica a sabedoria com a Torá. Essa conotação mais secular de sabedoria pode ter chegado ao seu ápice no contato do judaísmo com a filosofia ocidental durante o domínio helenista, mas sua origem pode remontar a períodos mais antigos e ter permanecido lado a lado com a tradição divergente. Um testemunho forte disso é a literatura do chamado círculo henoqueno (NICKELSBURG, 2003, p. 41).

As tradições para as quais a Torá reivindica a autoria de Moisés, o livro 1Enoch atribui a Henoque, com pouca ou nenhuma referência à Torá. Também a noção de aliança está quase completamente ausente na literatura henoquena. Tanto em Eclesiástico quanto em 1Enoch a sabedoria tem origem celeste. Contudo, para a literatura henoquena, o acesso à sabedoria é decorrente das viagens do vidente ao céu. $O$ caráter sapiencial de 1Enoch é evidente - pelo uso de formas literárias sapienciais tradicionais - especialmente em sua última e principal seção, a "Epístola de Henoque" em 1En 92-105 (NICKELSBURG, 2003, p. 42).

O uso de formas sapienciais de instrução ética em 1Enoch tem sua ênfase no julgamento divino a respeito da conduta humana. As instruções para a vida prática estão vinculadas a admoestações apocalípticas sobre recompensa e punição divina sobre atos humanos. Em 1Enoch se dá maior enfoque ao nexo entre as ações humanas e suas consequências do que ao cumprimento de mandamentos.

Portanto, torna-se notório que a época do segundo templo foi um período rico e criativo, isso é atestado pela diversidade literária e teológica de seus escritos sapienciais. Essa diversidade deriva do fato que movimentos religiosos visavam legitimar novas ideias ao mesmo tempo em que herdavam e transformavam antigas tradições. Nesse contexto, a centralidade da sabedoria e a perpetuação dos limites humanos diante da soberania divina estavam no cerne das questões, trazendo 
repercussões teológicas e sociológicas não somente para aquela época, mas para as gerações futuras.

\subsection{A sabedoria acessível a todos: o livro de Provérbios}

Tendo presente esse complexo e plural caminho do pensamento veterotestamentário sobre a sabedoria, é necessário considerar a questão se a sabedoria é acessível à razão humana e como se pode ter acesso a ela. Em Pr 8 temos uma amostra disso.

A saberia personificada, conforme Pr 8, é identificada através de várias imagens. Ali é demonstrado suas relações com o Criador, com o universo e com o ser humano. Também se enfatiza os bens que são por ela oferecidos e o público a quem se dirige e, finalmente, as consequências para quem a acolhe e para quem a rejeita. $O$ texto pode ser estruturado ${ }^{4}$ da seguinte forma:

\section{A 8, 1-3: a sabedoria chama;}

B 8,4-11: destinatários da sabedoria: os "filhos de adam";

\section{8, 12-21: os bens da sabedoria;}

B' 8,22-31: o prazer da sabedoria: instruir os "filhos de adam";

A' 8,32-36: bem-aventurado quem ouve seu chamado (a vida plena).

$\mathrm{Na}$ introdução ao discurso da sabedoria (v.1-3), a sabedoria é retratada como uma mulher gritando no alto das colinas, nas esquinas, na porta da cidade, na beira dos caminhos, para quem quiser ouvi-la. Isso mostra que, para pronunciar seu discurso, a sabedoria escolheu locais onde acontece a vida pública na sociedade antiga. Na porta da cidade se realizava o comércio, as assembleias religiosas e era onde também se administravam as questões de justiça. Nos demais locais as pessoas estavam se dirigindo para seu trabalho profissional diário. Enfim eram os lugares da vida social em tempos de paz. Portanto, os redatores finais do livro dos Provérbios, garantem ao leitor que a sabedoria não se faz ouvir em lugar privado, para um grupo de pessoas

\footnotetext{
${ }^{4}$ De uma maneira geral, este artigo assume a divisão de $\operatorname{Pr} 8$ feita por Gilbert e Aletti (1985, p. 15-28) com algumas modificações para melhor destacar o vocabulário utilizado pelo autor bíblico
} 
privilegiadas, a sabedoria vai até às pessoas, onde elas estão, é acessível a todo tipo de gente. A escolha desses locais elucida de onde e a quem é dirigida a sabedoria.

Um destaque especial deve ser dado ao vocabulário. O texto traz o verbo hebraico qara' (v. 1), geralmente traduzido por "clamar". Esse verbo também tem uma conotação de "convocar" ou "fazer uma proclamação" (STRONG, 1995, p. 127). A nota de rodapé da Bíblia de Jerusalém a Pr 8,3 afirma que a sabedoria age como "um vendedor ambulante" que tenta aos gritos atrair os fregueses exaltando a sua mercadoria (BÍBLIA, 2001, p. 1127). Podemos imaginar também um arauto em praça pública convocando a população para ouvir a leitura do novo decreto do soberano local.

O autor faz um paralelismo ${ }^{5}$ sinonímico com os termos qôl (voz) e ranan (gritar) (STRONG, 1995, p. 124 e p. 133). A sabedoria levanta a voz (v. 1) / gritando (v. 3). É impossível não ficar sabendo dessa convocação da sabedoria, os ouvintes terão que fazer uma opção: aderir ou não ao seu apelo. As consequências dessa opção serão mostradas no final do poema.

Os destinatários do discurso da sabedoria $(8,4-11)$ são os "filhos de adam" Na maioria dos casos, o termo bíblico "adam" não é nome próprio (Adão em português), mas significa apenas "a humanidade". Para o livro dos Provérbios, os destinatários do discurso da sabedoria não são aqueles que estão no templo, nem os eruditos entre os judeus, os escribas, os fariseus, os doutores da Lei; mas, ao contrário, com a expressão "filhos de adam" a sabedoria se dirige aos seres humanos independentemente de qualquer categoria ou ordem, estado ou condição.

Entretanto, as palavras que a sabedoria dirige aos seus ouvintes são um tanto deselegantes. A sabedoria os chama de "simples", "ingênuos" (pathah), isto é, os que não têm experiência ou maturidade para discernir e são suscetíveis tanto para o bem quanto para o mal e, portanto, podem ser facilmente enganados (STRONG, 1995, p. 118). São chamados também de "tolos", "bobos" (khesilim), ou seja, pessoas

${ }^{5} \mathrm{O}$ gênero literário sapiencial apresenta algumas peculiaridades na composição dos textos como a aliteração, a assonância, a hipérbole, além de diversas formas de paralelismo. No paralelismo sinonímico dois versos, com vocabulário diferente, retratam a mesma ideia: a sabedoria grita, o entendimento levanta sua voz. 
intelectualmente obtusas, com o coração lento ou pesado, pois o coração, de acordo com a cosmovisão semita, é a sede da inteligência (STRONG, 1995, p. 65).

Estes adjetivos não se dirigem de modo especial aos jovens, mas a todo o auditório, do qual a Sabedoria não faz uma ideia muito elevada. Isto porque a seus olhos, sem uma relação muito sólida com ela, os homens não podem erguer-se à verdadeira maturidade (GILBERT; ALETTI, 1985, p.17).

Portanto, a sabedoria é vital para os "filhos de adam" e o ensinamento oferecido por ela os levará ao bom êxito, pois os fará adquirir a verdadeira maturidade, a sagacidade e o discernimento. Nesse sentido, entre todas as coisas que são desejadas pelo ser humano, seja dinheiro, ouro puro ou pérolas, nada pode ser tão valioso quanto o bem precioso que a sabedoria oferece e que a torna acessível a todo ser humano que o queira receber.

A sabedoria promete, a quem a busca e a escuta, as seguintes coisas: a vida, a felicidade, mas, sobretudo, o encontro profundo com o Senhor. O contrário disso é o prejuízo de si mesmo, a morte e a ruptura com Deus. A sabedoria declara como bemaventurados aqueles que a ouvem com assiduidade. Estes não serão recompensados com riquezas ou poder, mas com um encontro profundo e íntimo com Deus, visto que ela é mediadora entre o ser humano e o Criador.

A sabedoria faz o papel de mediadora porque estava junto a Deus antes da criação, ela é proveniente de Deus, é sua filha primogênita, mas é experienciada como verdade, retidão e justiça, nas realidades humanas, e como mestra que ensina às pessoas o caminho do Senhor (GILBERT; ALETTI, 1985, p. 26-27).

Portanto, a benção da sabedoria não está reserva para um grupo seleto, ao contrário, ela é acessível a todos que a amam, mas o autor de Provérbios deixa bem claro que a única condição imposta pela sabedoria, para o recebimento de sua benção, é que ela seja amada e escutada $(8,21)$

\subsection{A sabedoria inacessível: Jó 28}

Da elaboração e reelaboração do material sapiencial realizada pelos sábios no período do segundo templo, o mais evidente é a necessidade do ser humano em obter a sabedoria, a sabedoria é essencial para o ser humano. O livro de Jó também partilha 
dessa opinião. Contudo, o livro de Jó tem uma posição diferente do livro de Provérbios a respeito da acessibilidade da sabedoria. Por isso, com a pergunta "onde está a Sabedoria" (Jó $28,12.20)$, Jó levanta a questão sobre a relação entre sabedoria e os limites do conhecimento humano.

Partindo do problema sobre o sofrimento do justo, diversas vezes ao longo do livro, Jó reivindica respostas de Deus para suas questões, admitindo não ter acesso a muitos aspectos da realidade, os quais lhe são ocultos e para as tradições sapienciais de sua época não conseguem dar uma resposta satisfatória. Essas tradições sapienciais naquela época eram unânimes ao fazer uma leitura da realidade sob a ótica do binômio benção-maldição, segundo o qual, se a pessoa fizesse o bem, receberia bênçãos de Deus, se fizesse o mal receberia castigo (maldição) ${ }^{6}$. Jó discorda da teologia da retribuição e reivindica que Deus reconheça sua integridade e explique seus sofrimentos. Em outras palavras, Jó exige um julgamento contra Deus, que pode ver tudo sob os céus, enquanto que para o ser humano a maior parte das coisas lhe permanece obscura.

Está presente em todo o livro essa discrepância entre os limites do humano e a clareza de tudo perante Deus. Jó reconhece sua ignorância na mesma intensidade com que aponta para seu sofrimento. Enquanto isso, em muitos capítulos, os amigos de Jó tentam defender a teologia da retribuição, exaltando a majestade de Deus e seu poder como forma de reduzir Jó ao silêncio.

Na conclusão do debate entre Jó e seus amigos, há uma manifestação de uma figura divina que não rejeita o sofrimento do personagem principal, ou seja, não confirma a teologia da retribuição, pois Deus não é controlado por ideologias humanas. Há uma grande diferença entre o ser humano e Deus. Ironicamente, o ser divino não explica o sofrimento do justo, mas exige que Jó, assumindo sua posição de homem, considere uma questão fundamental, os limites do conhecimento humano.

Essa argumentação tem como corolário a ignorância de Jó que é destacada no poema do capítulo 28 . O trecho de Jó 28 traz um contraste magnífico entre a habilidade

\footnotetext{
${ }^{6}$ As tradições sapienciais da época de Jó estão representadas pelos amigos que debatem com ele. Essa ideologia de ver a realidade a partir de bênção-castigo foi denominada pelos estudiosos de Teologia da Retribuição.
} 
humana para dominar a natureza e descobrir as coisas mais ocultas e a verdadeira sabedoria que não pode ser encontrada pela ciência humana. A estrutura ${ }^{7}$ de Jó 28 evidencia esse contraste:

A 28,1-12: o caminho do ser humano;

\section{B 28,13-20: onde é o lugar da sabedoria?;}

A' 28,21-28: o caminho da sabedoria.

O ser humano possui e exerce domínio sobre a natureza. Isso é exemplificado numa descrição da arte da mineração, ou seja, um caso em que o ser humano mostrava maior habilidade naquela época.

A atividade de mineração havia chegado a um grau considerável de desenvolvimento na época de Jó e deixava as pessoas admiradas com a inteligência humana. $A$ complexidade do processo de mineração parece ter exercido um fascínio sobre o autor do texto bíblico (SCHWIENHORST-SCHÖNBERGER, 2011, p. 141) que descreve as pedras preciosas escondidas nas entranhas escuras da terra onde nenhum ser vivo poderia habitar. No entanto, a inteligência humana, inventou meios de ir até lá em busca do que há de mais valioso. Os mineradores, com seu trabalho obstinado, cavam as rochas mais duras nas montanhas para encontrar os tesouros escondidos. Sua inteligência e persistência fazem com que o obstáculo mais difícil ceda diante deles (v. 9-11). Com grande arte e infatigável indústria, superando todas as dificuldades, finalmente chegam ao objeto desejado e encontram os preciosos tesouros que procuravam (SCHWIENHORST-SCHÖNBERGER, 2011, p.142-143).

Seu objetivo é mostrar que, apesar de a inteligência humana conseguir criar os meios necessários para descobrir o que há de mais oculto nas entranhas da terra, a verdadeira sabedoria não pode ser encontrada pela ciência humana, ou pela mera investigação. "Onde se achará a sabedoria?" (v. 12). Com esta pergunta se encerra a primeira estrofe do poema e a descrição das operações de mineração no tempo do autor bíblico.

\footnotetext{
${ }^{7}$ Em geral o artigo retoma a estrutura proposta por Schwienhorst-Schönberger (2011, p. 140-145), com alguns ajustes.
} 
Depois das gigantescas empreitadas que foram narradas, vem a questão que provoca um efeito impactante no leitor de Jó. A sabedoria é um valor infinitamente maior que todas as riquezas deste mundo, mas, apesar de sua ciência e habilidade, o ser humano desconhece totalmente onde se encontra esse tesouro. O ser humano não pode encontrar a sabedoria nos lugares onde descobre as pedras preciosas.

Na questão do v. 12, o autor usa o artigo para enfatizar que não se trata daquela arte de descobrir coisas da natureza ou de realizar as operações complicadas para conseguir riquezas, trata-se de ha-hokmah, a sabedoria sublime que está muito além do alcance do ser humano, que está numa profundidade que é insondável para os mortais (SCHWIENHORST-SCHÖNBERGER, 2011, p.144).

Os minérios valiosos e as pedras preciosas, embora ocultos, têm um lugar onde podem ser encontrados, e o ser humano sabe como alcançá-los e trazer à luz o que estava escondido, mas onde a sabedoria pode ser encontrada? onde está o lugar do entendimento? Não se encontra na terra dos viventes, nem no fundo do mar.

Da questão sobre onde está a sabedoria, o autor passa à pergunta sobre "de onde vem a sabedoria". Isso significa que ela é inacessível pelos esforços humanos. É inatingível porque o ser humano não dá conta de ir até ela. Porém, a sabedoria pode vir ao ser humano, ela se dá a conhecer. Contudo, isso não é automático, evidente, e nem é fruto de esforços. A vinda da sabedoria é uma ação de Deus porque somente ele sabe o caminho para a sabedoria, o lugar onde a sabedoria pode ser encontrada.

O que resta ao ser humano é abrir-se e acolher a sabedoria. O encontro com a sabedoria passa pelo encontro com Deus e não o contrário como afirmava $\operatorname{Pr} 8$ a respeito da sabedoria mediadora, pois sua origem estava em Deus, mas tinha fixado sua morada entre os seres humanos (SCHWIENHORST-SCHÖNBERGER, 2011, p.145-146).

Para Brueggemann (2014, p. 447), ocultamento da sabedoria tem a ver com o ocultamento de Deus que é invisível e age muitas vezes de forma tão discreta que seu agir é quase imperceptível. O profeta Isaías chega a essa constatação após anunciar a conversão das nações: "Entretanto tu és um Deus que se esconde, ó Deus de Israel, o Salvador" (Is 45,15). 
Israel se envaidecia de Deus estar presente em sua história, contudo, nos momentos mais cruciais, como no exílio na Babilônia, os exilados não conseguiam perceber a presença divina e muito menos entender o sentido do que estava acontecendo.

Javé estava presente e atento à vida de Israel de um modo oculto...ele intervém e se intromete de forma dramática e identificável na vida de Israel para concretizar sua justiça ... [mas] esses atos dramáticos da intervenção transformativa de Javé são realmente poucos e bem espaçados. Na maior parte do tempo, Israel deve se virar sem essas maravilhas (BRUEGGEMANN, 2014, 447-448).

Israel sabe que Deus não está sempre "visível", mas isto não significa que o Senhor da aliança esteja indiferente ao sofrimento do povo com o qual está comprometido. $\mathrm{O}$ ocultamento de Deus, portanto, não significa que tenha deixado de agir em favor de Israel, as intervenções perceptíveis de sua ação, apesar de não serem frequentes, servem de sinal para alimentar a fé de Israel a respeito do cuidado divino em relação ao povo, mesmo quando nos momentos mais críticos da história a presença de Deus não tenha sido percebida.

\section{CONSIDERAÇÕES FINAIS}

De uma preocupação com a vida prática, as tradições sapienciais passaram a refletir sobre o papel da sabedoria. As escolas sapienciais a personificaram e a consideraram como mediadora entre Deus e a humanidade, visto que a sabedoria tinha sua origem em Deus e permanecia entre os seres humanos. Movimentos sapienciais de forte cunho nacionalista identificaram a sabedoria com a Torá, enquanto os sábios da diáspora destacavam a universalidade da presença da sabedoria, visto que todas as obras da criação vieram a existir por meio dela.

O auge do movimento sapiencial em Israel foi exatamente a compreensão da sabedoria como um dom de Deus acessível a todos. A sabedoria estava disponível para ensinar indistintamente o caminho da felicidade aos seres humano.

De acordo com $\operatorname{Pr} 8$, a sabedoria faz o seu discurso em locais de vida pública e oferece o bem mais valioso que existe, a saber, o caminho para a felicidade que se resume em colocar-se de acordo com a ordem primordial da criação. Isto significa viver em consonância com a vontade de Deus, quem a acolhesse certamente seria feliz. 
Em outras palavras, Israel tinha em comum com outros povos escritos chamados sapienciais em formas literárias e temas próprios do Antigo Oriente Médio, mas os sábios de Israel acabaram reconhecendo que a sabedoria humana deveria estar de acordo com aquela sabedoria que tinha sua origem em Deus, que penetrava o mundo e presidira a criação.

Deus se aproxima do ser humano por meio dessa dádiva que é a sabedoria, que ele derrama sobre todos os seres vivos e com que cumula aqueles que o amam... Sendo sábios e tementes ao Senhor em sua prática da Torá, os seres humanos, por sua vez, acolhem e respondem a essa dádiva que vem de Deus (CERESKO, 2004, p. 145)

O temor do Senhor significa ser grato, reverenciar, servir, fazer a vontade do Senhor.

Gunneweg (2005, p. 326) é de opinião que numa época mais tardia a literatura sapiencial "recebeu a última formatação, caindo depois em uma crise intra-sapiencial", embora as raízes dessa crise sejam bem mais antigas. Em um primeiro momento dessa crise, esteve presente a questão levantada pelo livro de Jó: por que o justo sofre? A constatação que o leitor de Jó chega, a princípio, é a ineficácia da teologia da retribuição que não consegue explicar a realidade.

Já que a crise intra-sapiencial não chegou a nenhuma conclusão, a não ser a uma consciência da pequenez humana e da inacessibilidade da sabedoria, ou seja, dos limites do conhecimento e da linguagem humanos, em um segundo momento, em função de sua dinâmica interna, a sabedoria questionou todo o sistema de "pensar e planejar humanos" (GUNNEWEG, 2005, p. 333), ou seja, há um ceticismo em relação ao sistema sapiencial inteiro.

Em Jó, a resposta para a questão "onde está a sabedoria?" aponta para uma atitude de humildade diante da limitação humana em alcançar a sabedoria por suas próprias forças. Sendo assim, somente no encontro com Deus, doador da verdadeira sabedoria, e abrindo-se para acolhê-la como um dom, é que o ser humano pode acessá-la.

\section{REFERÊNCIAS}


ASENSIO, Victor Morla. Livros sapienciais e outros escritos. $3^{\underline{a}}$ ed. São Paulo: Ave Maria, 2008.

BÍBLIA. Português. Bíblia de Jerusalém: revista e ampliada. São Paulo: Paulus, 2002.

BRUEGGEMANN, W. Teologia do Antigo Testamento. Testemunho, disputa e defesa. Santo André: Academia Cristã - Paulus, 2014.

CERESKO, Anthony R. A sabedoria no Antigo Testamento: espiritualidade libertadora. São Paulo: Paulus, 2004.

DELL, Katharine. The book of Job as Sceptical Literature. Berlin; New York: Walter de Gruyter, 1991.

FOX, Michael V. Proverbs 1-9: a new translation with introduction and commentary. New Heaven: Yale University Press, 2000.

GILBERT, M e ALETTI, J-N. A Sabedoria e Jesus Cristo. São Paulo: Paulinas, 1985. Cadernos Bíblicos 32

GUNNEWEG, A. H. J. Teologia Bíblica do Antigo do Testamento: uma história da religião de Israel nas perspectiva bíblico-teológica: São Paulo: Loyola, 2005

NICKELSBURG, George W. E. Ancient Judaism and Christian Origins: Diversity, Continuity and Transformation. Minneapolis: Fortress Press, 2003.

SÆBØ, Magne. חכם hִkm Ser sabio. In: JENNI, Ernst (Ed.). Diccionario Teológico

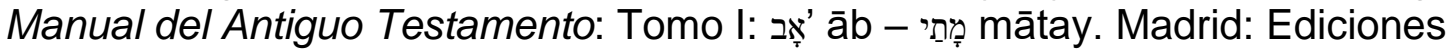
Cristiandad, 1985.

SCHWIENHORST-SCHÖNBERGER, L. Um caminho através do sofrimento. O livro de Jó. São Paulo: Paulus, 2011.

SILVA, Valmor da. O caminho da justiça na sabedoria dos provérbios. São Paulo: Paulus, 2019. Livro eletrônico.

STRONG, James. Hebrew and Aramaic Dictionary of the Old Testament. In: New Strong's Exhaustive Concordance. Nashville: Thomas Nelson Publishers, 1995.

VALERIO, Hanzel José Zúñiga. Qohelet: sabiduría irreverente. Acercamientos históricos, culturales y filosóficos. San José, Costa Rica: Escuela de Ciencias Bíblicas, UBL, 2018. Revista Aportes Bíblicos No. 25 (Suplemento). 